\title{
Plasma levels of immunoreactive atrial natriuretic factor increase during supraventricular tachycardia
}

\begin{abstract}
A significant diuretic and natriuretic response occurs during paroxysmal supraventricular tachycardia (SVT). Although the diuresis may be secondary to suppression of vasopressin secretion, the etiology of the natriuresis remains unexplained. To determine if atrial natriuretic factor (ANF) could contribute to the polyuric response during SVT, 10 patients were studied: five during spontaneous SVT and five during simulated SVT produced by rapid simultaneous atrial and ventricular pacing. Plasma immunoreactive ANF (IR-ANF) levels measured by radioimmunoassay were obtained at baseline (before and/or 24 to 48 hours after SVT) and after at least 15 minutes of SVT in all patients. During spontaneous and simulated SVT, IR-ANF was significantly elevated (mean $\pm S E ; 275 \pm 68 \mathrm{pmol} / L$ ) compared to baseline $(28 \pm 7 \mathrm{pmol} / \mathrm{L} ; \mathrm{p}=0.0036)$. Similar increases in IR-ANF were noted during both simulated and spontaneous SVT. To determine if this IR-ANF release was related to the increase in heart rate or the rise in right atrial pressure during SVT, IR-ANF levels were also measured in five patients with sinus tachycardia and in six patients with congestive heart failure. IR-ANF was significantly related to right atrial pressure $(r=0.93$; $p=0.0009)$ but not to heart rate $(r=0.46)$. Thus, IR-ANF is elevated during SVT and may contribute to the natriuretic response. The stimulus to IR-ANF secretion during SVT appears to be related to the rise in right atrial pressure rather than to the increase in heart rate. (AM HEART J $1986 ; 112: 923$.
\end{abstract}

John M. Nicklas, M.D., Lorenzo A. DiCarlo, M.D., Patrick T. Koller, M.D., Fred Morady, M.D., Emily A. Diltz, M.D., Yoram Shenker, M.D., and Roger J. Grekin, M.D. Ann Arbor, Mich.

A diuresis has been reported to occur in $20 \%$ to $50 \%$ of episodes of paroxysmal supraventricular tachycardia (SV'T).$^{1,2}$ Typically, this response occurs with heart rates greater than $120 \mathrm{bpm}$ after a duration of at least 10 to 30 minutes. ${ }^{1.2} \mathrm{~A}$ polyuric response has also been noted during episodes of atrial fibrillation, atrial flutter, and ventricular tachycardia. The characteristics of the diuresis during SVT include an increase in urine flow, volume, free water clearance, and sodium excretion and a decrease in urine osmolality. ${ }^{1-3}$

One possible pathophysiologic mechanism for this polyuric response during SVT is an increased secretion of a natriuretic factor or hormone. Recently, vasoactive peptides, termed atrial natriuretic factors

From the University of Michigan Medical Center.

Supported by grant HL 18575 from the National Heart, Lung, and Blood Institute, by the research service of The Veteran's Administration, and by National Institutes of Health Clinical Investigator Award HL 01170-02 (Dr. Nicklas).

Received for publication Feb. 27, 1986; accepted April 3, 1986.

Reprint requests: John M. Nicklas, M.D., 3910H Taubman, Cardiology Division, 1560 E. Medical Center D)., Ann Arbor, MI 48109-0399.
(ANF), have been isolated from animal ${ }^{4-6}$ and human ${ }^{7}$ atrial tissues, sequenced, and synthesized..$^{6-8}$ Infusion of synthetic human ANF into animals has been demonstrated to produce an increase in urine sodium, potassium, and chloride excretion, an increase in glomerular filtration rate and urine flow, an inhibition of aldosterone secretion, a relaxation of smooth muscle, and a systemic hypotensive effect. ${ }^{7-11}$ Infusion of synthetic human ANF into normal human volunteers produced a significant natriuresis, kaliuresis, and diuresis. ${ }^{12,13}$ In recent communications, plasma levels of ANF were reported to increase during paroxysmal SVT. ${ }^{13-15}$ In the present study, we have utilized a recently developed radioimmunoassay for ANF to determine the levels of immunoreactive ANF (IR-ANF) in human subjects during episodes of spontaneous and simulated SVT.

\section{METHODS}

Ten patients were studied; five were ubserved during spontaneous episodes of SVT and five underwent rapid simultaneous pacing of the atrium and ventricle to simulate SVT. The five patients with spontaneous SVT were 


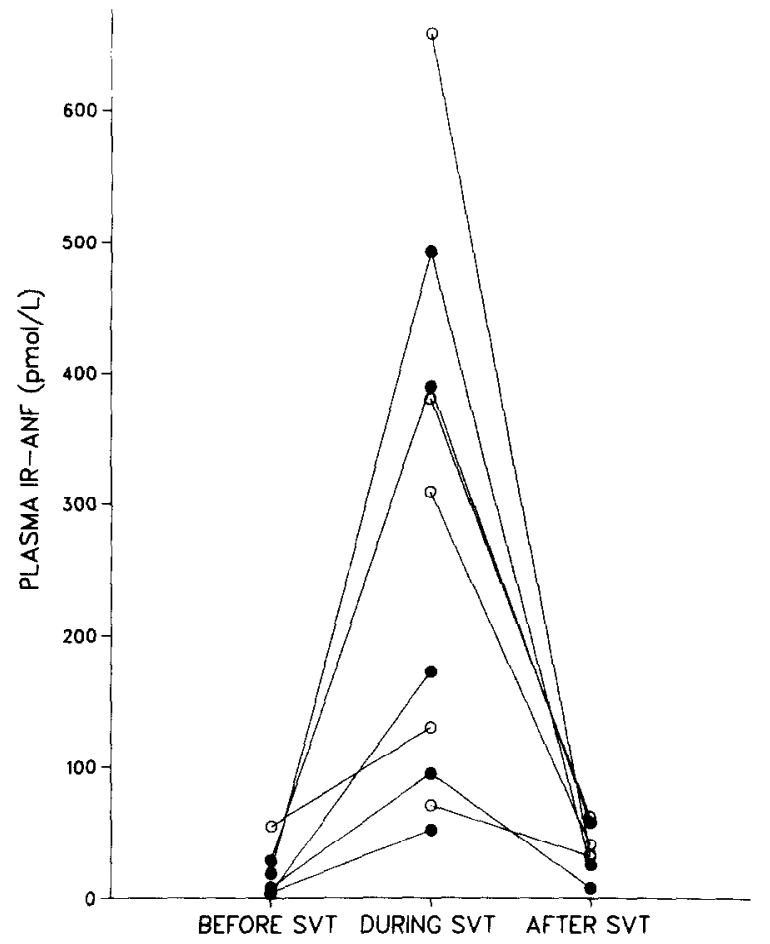

Fig. 1. Plasma IR-ANF levels drawn before, during, and 24 to 48 hours after SVT. Open circles = spontaneous SVT; filled circles $=$ simulated SVT.

$17,52,53,57$, and 71 years old, respectively; four were women and one was a man. A history of recurrent episodes of SVT was obtained from all five patients. One patient underwent electrophysiologic study (EPS) and was found to have an accessory atrioventricular pathway. The mechanism of the paroxysmal SVT was unknown in the other four patients.

The five patients undergoing paced simulation of SVT were $27,35,45,52$, and 54 years old, respectively; three were men and two were women. All five patients received simultaneous atrioventricular pacing during EPS. Indications for EPS included a history of Wolff-ParkinsonWhite syndrome in two patients, paroxysmal ventricular tachycardia and near syncope in one, symptomatic bradycardia in one, and recurrent palpitations in one. Accessory bypass pathways were demonstrated in the two patients with Wolff-Parkinson-White syndrome, sustained ventricular tachycardia was induced in the patient with near syncope, and results of EPS were normal in two patients. There was no history of angina or congestive heart failure in any of these 10 patients.

The five patients with spontaneous episodes of SV'T had heart rates of $148,160,177,186$, and $216 \mathrm{bpm}$. Plasma samples for ANF were collected after an arrhythmia duration of at least 20 minutes. In 4 of these patients, samples were drawn both during and 24 to 48 hours after the episode of SVT. In one patient SVT occurred spontaneously before scheduled EPS with a baseline level having been drawn before the arrhythmia began. All samples were drawn from peripheral venous sites.

The five patients who underwent rapid atrioventricular pacing were studied in the electrophysiologic laboratory preceding scheduled EPS. A $6 \mathrm{~F}$ bipolar, central-lumen electrode catheter, with an interpolar distance of $1 \mathrm{~cm}$, was inserted into the right femoral vein by means of the Seldinger technique. A second $6 \mathrm{~F}$ bipolar catheter was positioned in the right ventricular apex by means of the same technique. Forty milliliters of blood was drawn from the femoral vein cannula immediately before catheter placement. In one patient, SVT occurred spontaneously during catheter positioning. The patient was observed for 15 minutes and repeat blood samples were obtained; SVT was terminated by rapid atrial pacing. If SVT did not. occur spontaneously during catheter placement, then atrioventricular pacing was performed for 15 minutes with an atrioventricular interval of $0 \mathrm{msec}$, using a standard external dual-chamber pulse generator (Medtronic model 5330) and a current twice diastolic threshold. After 15 minutes of pacing at a rate of $160 \mathrm{bpm}$, a blood sample was drawn and pacing was then terminated. Surface ECGs were continuously recorded at 25 to $50 \mathrm{~mm} / \mathrm{sec}$ paper speed with the use of standard Electronics for Medicine recording equipment (VR 12, Honeywell Corporation, Pleasantville, N.Y.). Twenty-four hours after the pacing study, plasma samples were collected again for determination of IR-ANF.

Plasma samples for IR-ANF were obtained serially from one of the patients during and following a spontaneous episode of paroxysmal SVT. This patient was a 52 year-old man with a history of recurrent paroxysmal SVT. The patient was observed for 20 minutes at a heart rate of $186 \mathrm{bpm}$ and remained hemodynamically stable. Blood samples were drawn after 20 minutes of arrhythmia, and SVT was then terminated by carotid massage. Blood samples were also collected at 5, 10, 20, 30, 40, and 60 minutes following termination of SVT. A follow-up blood specimen was drawn 24 hours later.

Five patients with no known heart disease were studied during sinus tachycardia to determine the effect of heart rate alone on IR-ANF levels. These patients included two men and three women who were $22,42,44,53$, and 71 years old. Heart rates during sinus tachycardia were 102, 105, 112,142 , and $161 \mathrm{bpm}$. Plasma samples for ANF were collected during tachycardia lasting at least 20 minutes.

Six patients with congestive heart failure were studied to determine the effect of elevated right atrial pressure on IR-ANF levels. They included three men and three women who were $40,60,61,62,69$, and 80 years old. Three patients had ischemic cardiomyopathies; two were idiopathic and one was thought to be alcoholic in origin. Heart rates during plasma collection were $68,76,80,86,103$, and $109 \mathrm{bpm}$. Right atrial pressure was measured in five patients with congestive heart failure and three patients before and during simulated SV'T.

All blood specimens were collected in tubes containing EDTA, placed on ice, and centrifuged at $4^{\circ} \mathrm{C}$ with the use 
of a refrigerated centrifuge. The plasma samples were stored at $-70^{\circ} \mathrm{C}$ and extracted by means of C18 octadecylsilane cartridges (Sep-Pak, Waters, Milford, Mass.). The radioimmunoassay was performed with the use of an antibody against I-28 $\alpha$-human atrial natriuretic polypeptide ( $\alpha$-hANP) purchased from Peninsula Laboratories. Synthetic atriopeptin III was iodinated with chloramine T and separated by high-pressure liquid chromatography. Monoiodinated peptide was used as a tracer. The complete procedure has been previously described and tested. ${ }^{16}$

Group differences between patients at baseline and during SVT were compared by means of a paired $t$ test. All group values are expressed as mean \pm standard error of the mean. Linear regression analysis was used to examine relationships between plasma IR-ANF levels and other variables. All measurements obtained during normal sinus rhythm before SVT and 24 or more hours after SVT were assumed to be basal levels. In those instances in which levels were obtained both before and after SVT, the mean of these values was used.

\section{RESULTS}

The plasma concentrations of IR-ANF obtained in all patients with SVT are presented in Fig. 1. Three patients had samples drawn before, during, and 1 day following SVT. Three patients had samples drawn only before and during SVT. Four patients with spontaneous SVT had samples drawn during SVT and 24 hours later. The mean basal level of IR-ANF during normal sinus rhythm (NSR) was $28 \pm 7 \mathrm{pmol} / \mathrm{L}$. This was not significantly different from the level in normal volunteers of $18 \pm 2 \mathrm{pmol} /$ $\mathrm{L}$, as determined by our laboratory $(p=N S) \cdot{ }^{16}$ In every case there was an increase in plasma IR-ANF concentration during SVT compared to baseline levels during NSR. The mean plasma IR-ANF level during SVT was elevated, $275 \pm 68 \mathrm{pmol} / \mathrm{L}$ $(p=0.0036)$, compared to basal levels. Similar elevations of plasma IR-ANF occurred in patients with spontaneous and simulated SVT. Plasma IR-ANF levels obtained before SVT $(20 \pm 8 \mathrm{pmol} / \mathrm{L})$ were similar to those obtained 24 to 48 hours after SVT $(32 \pm 7 \mathrm{pmol} / \mathrm{L})$.

Serial plasma IR-ANF samples obtained from one patient during and following a spontaneous episode of SV'T are shown in Fig. 2. This patient demonstrated a dramatic elevation in plasma IR-ANF concentration during SVT (659 pmol/L) compared to levels at baseline NSR obtained 24 hours later ( 33 $\mathrm{pmol} / \mathrm{L})$. The samples obtained reveal a rapid decrease in IR-ANF during the first 10 minutes following termination of SVT with a gradual taper in levels afterward.

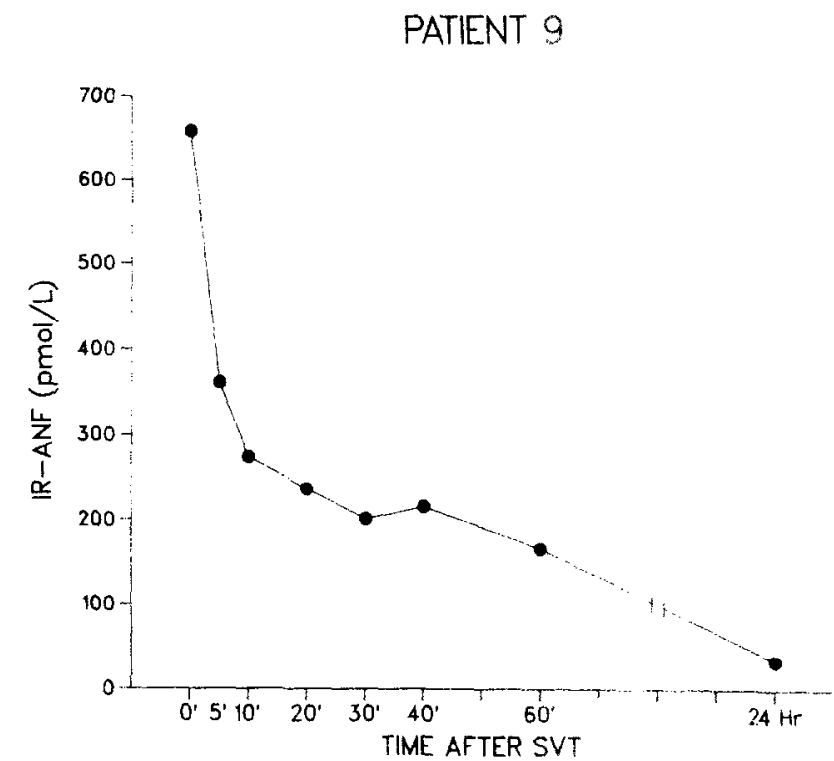

Fig. 2. Plasma IR-ANF concentrations during and after a single episode of spontaneous SV'T. Initial sample drawn, after 20 minutes of SVT (heart rate $186 \mathrm{bpm}$ ), is indicated at time 0 minutes. SVT was terminated immediately after the initial specimen was obtained.

Levels of plasma IR-ANF in patients during SVT $(275 \pm 68 \mathrm{pmol} / \mathrm{L})$ are compared with those from patients with sinus tachycardia $(38 \pm 8 \mathrm{pmol} / \mathrm{L})$ and congestive heart failure $(316 \pm 91 \mathrm{pmol} / \mathrm{L})$ in Fig. 3 . There was no relationship between IR-ANF levels and sex $($ males $=158 \pm 75 \mathrm{pmol} / \mathrm{L}$, females $=103 \pm$ $57 \mathrm{pmol} / \mathrm{L} ; p=\mathrm{NS})$, age $(r=0.29 ; p=\mathrm{NS})$, or heart rate $(r=0.46 ; p=\mathrm{NS})$.

Right atrial pressure was significantly related to IR-ANF levels $(r=0.93 ; p=0.0009)$ at baseline in the patients with SVT and congestive heart failure as shown in Fig. 4. During SVT, right atrial pressure and plasma IR-ANF rose in three patients from $1.9 \pm 1.3$ to $6.7 \pm 0.8 \mathrm{~mm} \mathrm{Hg}$ and from $13 \pm 9$ to $179 \pm 130 \mathrm{pmol} / \mathrm{L}$, respectively. The predicted IR. ANF level during SVT for these patients was 151 $\mathrm{pmol} / \mathrm{L}$.

\section{DISCUSSION}

The pathophysiology underlying the diuretic response associated with SVT has been only partially elucidated. Animal studies have shown that the reflex diuretic response which occurs during rapid atrial pacing can be inhibited by prior hypophysectomy, suggesting a neurohumoral control mechanism. ${ }^{17} \mathrm{~A}$ recent report demonstrated that in a patient experiencing an episode of atrioventricular nodal tachycardia, plasma and urine vasopressin 


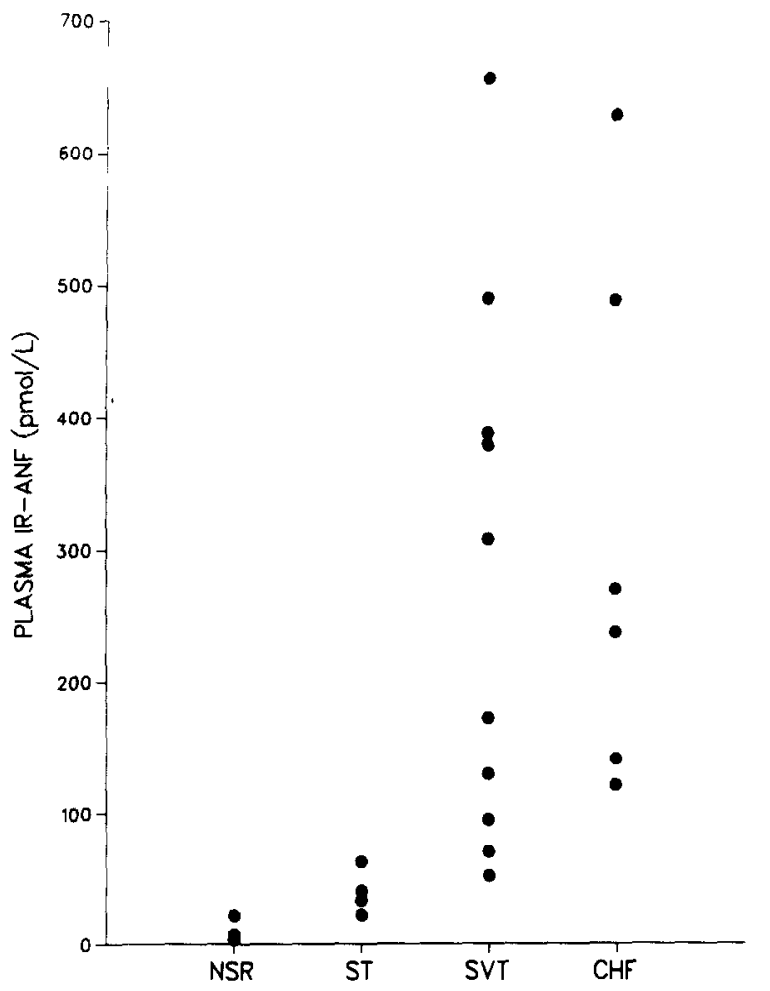

Fig. 3. Plasma IR-ANF levels in patients with normal sinus rhythm (NSR), sinus tachycardia $(S T)$, supraventricular tachycardia $(S V T)$, and congestive heart failure (CHF).

levels were suppressed. ${ }^{18}$ Thus the increased free water clearance during SVT could be linked to a suppression of vasopressin. Left atrial stretch receptors and vagal afferent pathways have been implicated in the mediation of vasopressin inhibition. Distention of the left atrium by inflation of a balloon within that chamber produces a reflex water diuresis which can be prevented by prior cervical vagotomy and cardiac denervation. ${ }^{19,20}$ During left atrial distention a decrease in plasma vasopressin concentration has been demonstrated to occur. ${ }^{21}$ Thus conditions associated with an increase in left atrial pressure may stimulate atrial stretch receptors and afferent parasympathetic pathways producing a suppression of vasopressin release. Since SVT is associated with an increase in both the mean atrial pressure and the amplitude of atrial pressure pulsations, ${ }^{22}$ this may be the mechanism through which the reflex water diuresis is stimulated. Although vasopressin inhibition may account for the increase in free water clearance during SVT, it does not explain the associated natriuresis.

This study demonstrates thta IR-ANF is significantly increased during episodes of SVT. The levels of IR-ANF during SVT for the entire group were

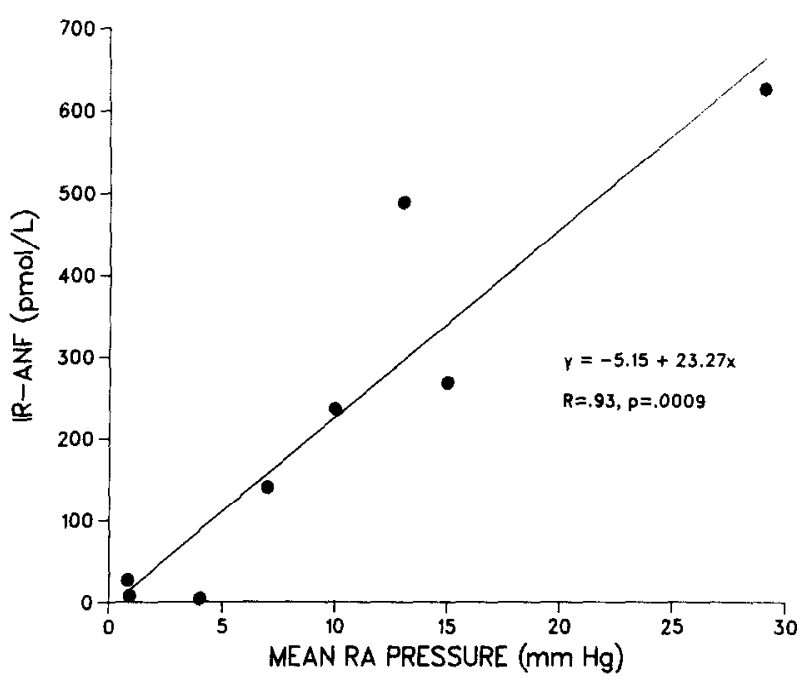

Fig. 4. Linear regression of plasma levels of IR-ANF as a function of right atrial $(R A)$ pressure.

found to be almost tenfold higher than those during normal sinus rhythm and returned to baseline within 24 hours. Similar increases in plasma IR-ANF occurred in patients with spontaneous SVT and in patients with simulated SVT, suggesting that the phenomenon was not simply secondary to electrical stimulation of the atrium during pacing. The data collected from a single patient during spontaneous SVT suggest that the IR-ANF elevation is a transient response that occurs during the arrhythmia and rapidly decreases following termination of the event. The presence of elevated IR-ANF levels 1 hour after termination of SVT suggests either continued release of IR-ANF or a plasma half-life greater than 10 minutes. Since preliminary results imply that the half-life of the polypeptide in humans is less than 5 minutes, the first possibility appears most likely. ${ }^{13,23}$ Inactive forms of ANF, which are immunoreactive but with longer halflives, could also account for this difference.

The relationship of these elevations in plasma IR-ANF to a natriuresis is supported by previous infusion studies in humans. Absolute IR-ANF levels between 40 and $110 \mathrm{pmol} / \mathrm{L}$, produced by infusion of $\alpha$-hANP in healthy subjects, have been associated with increases in urinary sodium concentration. ${ }^{13}$ Bolus infusions of smaller total doses of $\alpha$-hANP yielded significant increases in urinary volume $(2 x)$ and sodium $(4 X)$ compared to placebo. ${ }^{12}$ Thus the plasma IR-ANF levels during SVT in this study appear to have been sufficiently high to produce a natriuresis in at least six of the patients.

The large variability in the individual absolute and relative increases in IR-ANF during SVT may 
be clinically significant. Although IR-ANF significantly increased from basal levels during the arrhythmia in all patients, a diuretic response associated with SVT occurs in only $20 \%$ to $50 \%$ of episodes. ${ }^{1,2}$ The absence of diuresis despite a rise in IR-ANF may be the result of several factors. Again, the assay utilized may measure not only active ANF peptides but also inactive precursor forms. More likely, threshold concentrations sufficient to produce a diuretic response may not be achieved in every case. In addition, the stimulus for natriuresis during SVT may be multifactorial, depending not only upon changes in plasma ANF concentrations but also upon other neural, humoral, and hemodynamic factors.

This study suggests that the primary stimulus for release of ANF during SVT is a rise in right atrial pressure and not the increase in heart rate, per se. Patients with sinus tachycardia had no significant increase in IR-ANF, and there was no relationship between the peak IR-ANF level and the SVT heart rate. Increasing atrial pressure in rats through intravenous infusion of saline solution ${ }^{24}$ or intraatrial balloon dilatation ${ }^{25}$ has also been reported to increase plasma ANF. The rise in right atrial pressure during SVT in this study was, in part, the result of simultaneous contraction of the atrium and ventricle with the tricuspid valve closed. Right atrial pressure may fall with sinus tachycardia when this valve remains open during atrial systole. Thus the relatively small rises in IR-ANF previously reported during atrial pacing may be secondary to smaller increments in right atrial pressure ${ }^{13-15}$ The present study, however, does not uniquely define right atrial pressure as the primary determinant of ANF release. Other hemodynamic variables may be even more closely related. Atrial distention rather than intraatrial pressure may be the final stimulus.

The IR-ANF assay used in this study has high affinity for hANP (95\% to $100 \%$ binding) and essentially no cross reactivity with furosemide, angiotensin I, angiotensin II, bradykinin, cosyntropin, $\alpha$-MSH $[\alpha$-melanocyte stimulating hormone], somatostatin, $\beta$-endorphin, or vasopressin $(<0.2 \%) \cdot{ }^{16}$ Although, as with any radioimmunoassay, inactive forms of the polypeptide may have been measured, the specificity of the assay for biologically active ANF appears to be high. Reversed-phase, high-performance liquid chromatography of human plasma extracts before and after exogeneous hANP administration has shown only one major peak with a retention time similar to that of hANP. ${ }^{26}$ This suggests that inactive forms of the polypeptide do not circulate and that the IR-ANF assay used in this study primarily detected biologically active ANF.

The observations from this study suggest that the mechanism behind the natriuretic and diuretic responses to SVT may involve the release of ANF. The release of ANF, like the inhibition of vasopressin, appears to be mediated by hemodynamic changes in the atrium. Paroxysms of SVT may stimulate the release of IR-ANF by increasing intraatrial pressure. The combination of decreased vasopressin and increased ANF during SVT may thus explain both the increase in free water clearance and the increase in urinary sodium excretion associated with this arrhythmia. These proposed physiologic reflexes emphasize the importance of the atrium in the regulation of fluid and electrolyte homeostasis.

This study imputes a possible role for ANF in the natriuresis associated with SVT. Additional observations must be made to verify its role. The natriuresis must be documented by careful sampling of urinary flow and electrolytes, and the renal response to ANF infused to levels obtained during SVT must be determined. Finally, the mechanism through which ANF is released must be further defined.

\section{REFERENCES}

1. Wood P. Polyuria in paroxysmal tachycardia and paroxysmal atrial flutter and fibrillation. Br Heart J 1963:25:273-282.

2. Luria MH, Adelson EI, Lochaya S. Paroxysmal tachycardia with polyuria. Ann Intern Med 1966;65:461-470.

3. Ghose RR, Jockes AM, Kyriachou EH. Renal response to paroxysmal tachycardia. Br Heart J 1965;27:684

4. deBold AJ, Borenstein HB, Veress AT, Sonnenberg H. A rapid and potent natriuretic response to intravenous injection of atrial myocardial extracts in rats. Life Sci 1981:28:89. 94.

5. Currie MG, Geller DM, Cole BR, et al. Bioactive cardiac substances: Potent vasorelaxant activity in mammalian atria. Science 1983;22 1:71-73.

6. Flynn TG, deBold ML, deBold AJ: The amino acid sequence of an atrial peptide with potent diuretic and natriuretic properties. Biochem Biophys Res Commun 1983;117:859. 865.

7. Kangawa K, Matsou H. Purification and complete amino acid sequence analysis of $\alpha$-human atrial natriuretic polypeptide ( $\alpha$-hANP). Biochem Biophys Res Commun 1984:118:131 139.

8. Atlas SA, Kleinert HD, Camargo M.J, al. Purification, sequencing and synthesis of nalriuretic and vasoactive rat atrial peptides. Nature 1984;309:717-719.

9. Burnett JC Jr, Granger JP, Opgenorth TI. Effects of synthetic atrial natriuretic factor on renal function and renin release. Am J Physiol 1984;247:F863-866.

10. Maack T, Marion DN, Camargo M.JF, et al. Effects of auriculin (atrial natriuretic factor) on blood pressure, renal function and the renin-aldosterone system in dogs. Am I Med 1984;77:1069-1075.

11. Atarashi K, Murlow PJ, Saenz FR, Shajdar R, Rapp J. Inhibition of aldosterone production by an atrial extract. Science 1984;223:992-994.

12. Richards AM, Ikram H, Yandle TG, Nicholls MG, Webster MWI. Espiner EA. Renal, hemodynamic and hormonal 
effects of human alpha atrial natriuretic peptide in healthy volunteers. Lancet 1985; 1:545-549.

13. Tikkanen I, Fyhrquist F, Metsarinne K, Leidenius R. Plasma atrial natriuretic peptide in cardiac disease and during infusion in healthy voluntcers. Lancet 1985;1:66-69.

14. Schiffrin EL, Gutkowski J, Kuchel O, Cantin M. Plasma concentration of atrial natriuretic hormone in a patient with paroxysmal atrial tachycardia [Letter] N Engl J Med 1985; 312:1196-1197.

15. Yamaji T, Ishibashi M, Nakaoka H, Imataka K, Amano M, Fujii J. Possible role for atrial natriuretic peptide in polyuria associated with paroxysmal atrial arrhythmias. Lancet 1985; 1:1211.

16. Shenker Y, Sider RS, Ostafin EA, Grekin RJ. Plasma levels of immunoreactive atrial natriuretic factor in healthy subjects and in patients with edema. J Clin Invest 1985;76:16841687.

17. Boykin J, Cadnapaphornchai P, McDonald KM, Schrier RW. Mechanism of diuretic response associated with atrial tachycardia. Am J Physiol 1975;229:1486-1491.

18. Canepa-Anson R, Williams $M$, Marshall J, Mitsuaka $T$, Lightman S, Sutton R. Mechanism of polyuria and natriuresis in atrioventricular nodal tachycardia. Br Med J 1984; 289:866-868
19. Henry JP, Gauer OH, Reeves JL. Evidence of the atrial location of receptors influencing urine flow. Circ Res 1956;4:85-90.

20. Fater DC, Schultz HD, Sundet WD, Mapes JS, Goetz KL. Effects of lcft atrial stretch in cardiac denervated and intact conscious dogs. Am J Physiol 1982;242:H1056-1064.

21. Ledsome JR, Wilson N, Ngsee J. Time course of changes in plasma vasopressin during atrial distention. Can d Physiol Pharmacol 1982;60:1210-1218.

22. Goldreyer BH, Kastor JA, Kershbaum MD. The hemodynamic effects of induced supraventricular tachycardia in man. Circulation 1976;54:783-789.

23. Kuribayashi T, Nakazato M, Tanaka M, et al. Renal effects of human $\alpha$-atrial natriuretic polypeptide [Letter]. N Engl $J$ Med 1985;312:1456

24. Lang RE, Tholken $\mathrm{H}$, Ganten $\mathrm{D}$, Luft EC, Ruskoaho $\mathrm{H}$ Unger T. Atrial natriuretic factor-a circulating hormone stimulated by volume loading. Nature 1985;314:264-266.

25. Dietz JR. Release of natriuretic factor from rat heart-lung preparation by atrial distention. Am J Physiol 1984; 247:R1093-1096.

26. Yamaji T, Ishibashi M, Takaku F. Atrial natriuretic factor in human blood. J Clin Invest 1985;76:1705-1709.

\title{
Ventricular arrhythmias during reperfusion
}

\begin{abstract}
Accelerated idioventricular rhythm has been used as a marker for coronary reperfusion. The incidence of accelerated idioventricular rhythm and ventricular tachycardia was evaluated in $\mathbf{5 2}$ consecutive patients undergoing thrombolysis with intracoronary streptokinase during acute myocardial infarction. Complete 12-hour Holter recordings during and after intracoronary streptokinase were obtained in 39 patients. Reperfusion was documented in 17 patients (44\%), no reperfusion in $14(36 \%)$, and subtotal occlusion in eight $(20 \%)$. Accelerated idioventricular rhythm occurred in $83 \%, 57 \%$, and $63 \%$ of patients by group, respectively $(p>0.05)$. Ventricular tachycardia occurred in $100 \%, 71 \%$, and $100 \%$ of patients by group, respectively $(p<0.05)$. These data demonstrate that accelerated idioventricular rhythm is not specific for reperfusion and cannot be used as a marker for this event, and that ventricular tachycardia is more common with reperfusion and subtotal occlusion. (Am HeART J 1986;112:928.)
\end{abstract}

Frederick C. Miller, M.D., Mitchell W. Krucoff, M.D., Lowell F. Satler, M.D., Curtis E. Green, M.D., Ross D. Fletcher, M.D., Albert A. Del Negro, M.D., David L. Pearle, M.D., Kenneth M. Kent, M.D., Ph.D., and Charles E. Rackley, M.D. Washington, D.C.

Nonsurgical reperfusion for acute myocardial infarction has become a widely accepted intervention. Noninvasive markers for successful reperfusion,

From the Department of Medicine, Division of Cardiology, Georgetown University Hospital.

Received for publication March 14, 1986; accepted April 22, 1986.

Reprint requests: Charles E. Rackley, M.D., Georgetown University Huspital, Division of Cardiology, Room 2201, Main Hospital, 3800 Reservoir Rd., N.W., Washington, DC 20007. such as specific arrhythmias, resolution of ST segment shift, and creatinine-kinase enzyme curves, are undergoing evaluation for use in the determination of candidates who might benefit from angiography after receiving an intravenous thrombolytic agent. Accelerated idioventricular rhythm has been noted at the moment of reperfusion with intracoronary streptokinase ${ }^{1}$ and has shown promise as such a marker. A systematic quantification of ventricular tachyarrhythmias during thrombolytic therapy with 